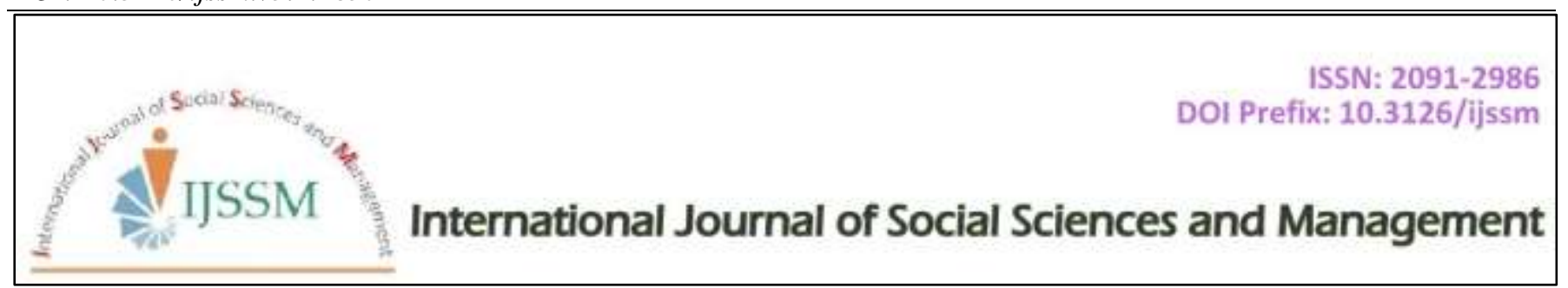

Case Study

\title{
Society's Perception on Residences in Development Area Attachment: A Case Study of PLPBK in Tulusrejo Village, Lowokwaru Sub- District, Malang City
}

\author{
Devi Triwidya Sitaresmi ${ }^{1}$, Ismu Rini Dwi Ari ${ }^{1}$ and I Nyoman Suluh Wijaya ${ }^{1}$ \\ ${ }^{1}$ Department of Civil Engineering, Urban and Regional Planning Study, Brawijaya University, Indonesia \\ *Corresponding author email : sitaresmidevie@gmail.com
}

\begin{abstract}
This study involved residents of RT 02 and RT 03, Tulusrejo sub-district. The setting of this study was one of the government's target residence related to the project of Community-Based City and Residence Planning or Penataan Lingkungan Pemukiman Berbasis Komunitas (PLPBK), which success depended on society's participation. Social bonds that result from long-term social interaction and life journey create emotional feeling upon their residences (Hummon, 1992). The place where people live and do their daily activities has certain deep meaning for them (Kyle et al, 2004), which at the same time affects the social psychological domain called place attachment (Lewicka, 2011). Thus, it was necessary to create strong social bonds and strengthen residents' place attachment feeling for the success of the PLPBK program. In this study, social network mapping was analyzed using the Social Network Analysis (SNA). Meanwhile, to explain residents' perception on their residence, Multidimensional Scaling was used. The result of this study exhibits that some social groups were formed upon certain similarities and membership of a certain organization. Besides, social groups were also formed by similar community attachment.
\end{abstract}

Keywords: Place attachment; Community attachment; Social Network Analysis (SNA); Multidimensional Scaling

\section{Introduction}

Poverty has been complex and comprehensive social phenomena that occur in Indonesia which requires the government to design a set of systematic and comprehensive anti-poverty program that involves various parties (government, society, non-government organization) (Noor, 2014). The government, through the Directorate of General Cipta Karya from the Ministry of
Public Works, tries to give strong attention to improving the quality of residences and social welfare. The effort is realized in the form of a set of comprehensive and integrated program that includes physical development (infrastructure and housing), social development as well as economic development through community empowerment called PLPBK program (Directorate of Housing Development,

\section{Cite this article as:}

D.T. Sitaresmi et al (2018) Int. J. Soc. Sc. Manage. Vol. 5, Issue-1: 46-50. DOI: 10.3126/ijssm.v5i1.18502

$1 *$ Corresponding author

Devi Triwidya Sitaresmi,

Department of Civil Engineering, Urban and Regional Planning Study, Brawijaya University, Indonesia

Email: sitaresmidevie@gmail.com

Peer reviewed under authority of IJSSM

(C) 2018 International Journal of Social Sciences and Management

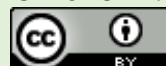

This is an open access article \& it is licensed under a Creative Commons Attribution 4.0 International License (https://creativecommons.org/licenses/by/4.0/) 
Directorate General of Cipta Karya, Ministry of Public Development, 2015).

PLPBK is a program that is designed to improve the quality of residences through a participatory approach, in which the success of the program is determined by society's participation. Community attachment appears as the result of social interaction which promotes emotional feeling toward society's residences where they live and share their life journey (Hummon, 1990). The houses where people live and do daily activities give them certain emotional bonds (Kyle et al, 2004) that affect the social and psychological domain called place attachment (Lewicka, 2011). Regarding the central government's program to improve the quality of residences, the government of Malang city in the RPJMN 2015-2019 is committed to set Malang city free from "slum area" by 2019 through the program Penataan Lingkungan Permukiman Berbasis Komunitas (PLPBK).

In relation to the participatory-based $P L P B K$ program, this study attempted at exploring the similar perception of individuals within certain society on the concept of residences as the place to stay permanently. Individuals' perception were then analyzed in order to form new social groups, creating strong bonds between the individuals and their homes.

Each individual of a certain social group was then observed to see if there was any similar perception and the place attachment feeling was also analyzed through personal variables, community, and environment (Raymond et al., 2000).

Social relation formed in the setting of this study was then identified by observing inter-individual interaction within the society including the most frequent activity, level of participation, and the role of the group or the key person of the society. The data were then analyzed using social network analysis method (Wasserman \& Faust, 1994). The result of the identification was then regarded as an input used to describe the social groups in RT 02 and $R T 03 R W$ 09, Tulusrejo.

\section{Material and Methods}

\section{Social Network Analysis}

This study employed a mixed-method research method in which the data related to the social groups were obtained from the respondents which later were used to map the social networking pattern in the society using the social network analysis (SNA). SNA is defined as a technique of mapping and measurement of communication and interaction that occur within local social groups including the members of the group, certain society, information, and any social services in the group. Social network refers to studies on social entities (such as someone's role in an organization) and interaction as well as a relation between the entities (Wasserman \& Faust, 1994). SNA included:

1. Analysis on the level of participation of the respondents in the implementation of PLPBK program. The level of participation was measured by summarizing the diagonal values in the matrix which were then divided by the number of respondents.

2. Density test was administered to see the density of the interaction in the society. Within the density analysis, inclusivity refers to the number of the connected dots (individuals or actors who did not join any organization).

$$
\text { Inclusiveness }=\frac{\left(n-n_{0}\right)}{n}
$$

Where

$$
\begin{aligned}
& \mathrm{n}=\text { Number of actors } \\
& \mathrm{n}_{0}=\text { Number of actors who did not join any organization }
\end{aligned}
$$

The density test was administered in the form of indirect density analysis considering the narrow scope of the study which is limited to the neighboring groups. Hence, it was assumed that individual A knew individual B and vice versa.

$$
\text { Density of indirected graph }=\frac{2 l}{n(n-1)}
$$

Where,

$$
\begin{aligned}
& \mathrm{l}=\text { Number of inter-actor connection line } \\
& \mathrm{n}=\text { Number of actors }
\end{aligned}
$$

3. Analysis of centrality was administered to see the central actors in the implementation of PLPBK program. Analysis was conducted through 3 steps; degree centrality (determining the central actors based on the number of the networking toward the respondents), betweenness centrality (determining the central actors who abridge the interaction among respondents), and closeness centrality (determining the central actors through the closest relationship among respondents). Matrix data on the membership of the respondents were used to measure the centrality using the UCINET software.

\section{Multidimensional Scaling}

Multidimensional Scaling (MDS) is a data analysis technique used to analyze similarities or varieties of a certain object. This analysis allows researchers to read and interpret the data comprehensively using visual representation (Borg and Groenen, 2005). In this study, similarities and differences of the data were measured based 
on three variables of place attachment (Raymond, Brown, and Weber 2010) including:

1. Personal Variable. The sub-variables included place identity and place dependence.

2. Social Variable, which sub-variables included community attachment.

3. The environmental variable with connectedness to nature as the sub-variable.

\section{Data Collection Method}

The data of this survey research were collected from questionnaires, observation and direct interview with the respondents to find out their social network. The questionnaires and interview attempted at exploring respondents' organizational memberships, views on the organization, frequency of organizational gathering, and the role of actors in the organization. In addition, a secondary survey was done to complete the data with the profile of Tulusrejo village and reports of PLPBK program.

The respondents of this study included 47 families in RT 02 and 51 families in RT 03 RW 09 Tulusrejo village. Only the heads of the families were interviewed as the representative of the family, no to mention that they were the ones who hold certain roles in the organization and directly experienced the $P L P B K$ program.

\section{Results and Discussion}

\section{Social Networking in RT 02 and RT 03 RW 09 Tulusrejo Village}

The result of the data analysis exhibits that the participation level of residents in RT 02 was at 1.40 , while the residents of RT 03 obtained 1.50. This result indicates that each respondent in both RT 02 and RT 03 enrolled to the same organizations. The organizations were Koran recitation group and social gathering. The values 1.40 and 1.50 exhibit that the participation was at the intermediate level.

The result of the density test of RT 02 and RT 03 exhibit similar value at 0.69 , in which the closer the value to 1 , the higher the opportunity for the respondents to meet each other in the organization. Therefore, based on the density value, it can be stated that the similarity level of the residents in joining certain organization was at the intermediate level.

The result of centrality test conducted to the residents of RT 02 exhibits that the maximum degree was at 0.80 , whilst the minimum degree was 0 . This result indicates that the respondents had relatively high roles of centrality in supporting the success of the $P L P B K$ program. The closeness value was also included in the high category at the maximum value of 0.90 and a minimum value of 0.38 . Hence, it can be seen that all of the respondents from RT 02 who joined certain organization were interconnected to each other in one or two organizations.
The centrality test administered to the respondents of RT 03 exhibits that the maximum degree was at 0.84 and the minimum degree was 0 . These values explain that the centrality of the respondents in participating in the PLPBK program was high. The closeness value was also high at the maximum value of 0.89 and the minimum value of 0.37 . These results indicate that the respondents of RT 03 who joined certain organization were inter-connected in one or two organizations only. The high closeness value is also followed by low betweenness value that is close to zero, which means that all of the respondents had a similar role, and nobody held the role as mediator within the network.

\section{Residents' Perception on Their Residences in RT 02 and RT 03, Tulusrejo Village}

Explanation on the spatial map of residents' perception on RT 02 as a place to live is illustrated in Fig. 1.

1. There are two major groups in the spatial map regarding residents' perception in RT 02 which is divided into self-identity group and accessibility.

2. Social condition (row 3) and environmental condition (row 4) do not appear to be the main reasons for the residents in choosing places to live, as seen from the absence of the respondents in the social condition (row 3) and environmental condition (row 4).

3. Based on the dimension 1 (self-identity): coordinate points that close to the right side exhibit that the respondents have similar reasons related to self-identity.

4. Seen from the dimension 3 (accessibility): coordinate points located on the upper side exhibit residents' similar reasons related to accessibility as the sub-variable.

5. Quadrant 1 consists of A3, A5, A11, A16, A23, A27, A42, and A47. Based on the result of the survey and mapping of residents' perception, it can be seen that in this quadrants, respondents tended to choose accessibility (row 2) as the main reason for choosing their residences, followed by the social condition (row 3), environmental condition (row 4), and self-identity (row 1).

6. Quadrant II consists of A12, A18, A22, A33, A38, A39, indicating the similar perception influenced by accessibility (row 2), followed by the social condition (row 3), self-identity (row 1), and environmental condition (row 4). In addition, respondents A19, A30, A34, A40, A44 stated that accessibility was the main consideration. However, self-identity (row 1), social condition (row 3) and environmental condition (row 4) appeared to be the main reasons in the further phase.

7. Quadrant III consists of A1, A6, A9, A14, A15, A17, A20, A24, A26, A28, A29, A32, A35, A37, 
A41, and A43. Respondents in this quadrant chose self-identity (row 1) as the main reason, followed by accessibility (row 3), social condition (row 3 ) and environmental condition (row 4).

8. Quadrant IV consists of A7, A13, A45, A46 who put the self-identity (row 1) as the main reason, followed by social condition (row 3), environmental condition (row 4) and accessibility (row 3). Yet, some respondents A2, A4, A8, A10, A21, A25, A28, A31, A36 mentioned that selfidentity (row 1 ) was the main reason, followed by the social condition (row 3 ), accessibility (row 2) which is different from the first group (in the first group, accessibility is put as the last reason), and the environmental condition (row 4) was the last reason.

Based on the grouping of respondents' reason in choosing their residences, it can be seen that 28 respondents $(60 \%)$ put self identity as the main reason, while 19 respondents (40\%) chose accessibility as the main reason for staying in RT 02 RW 09 Tulusrejo Village.

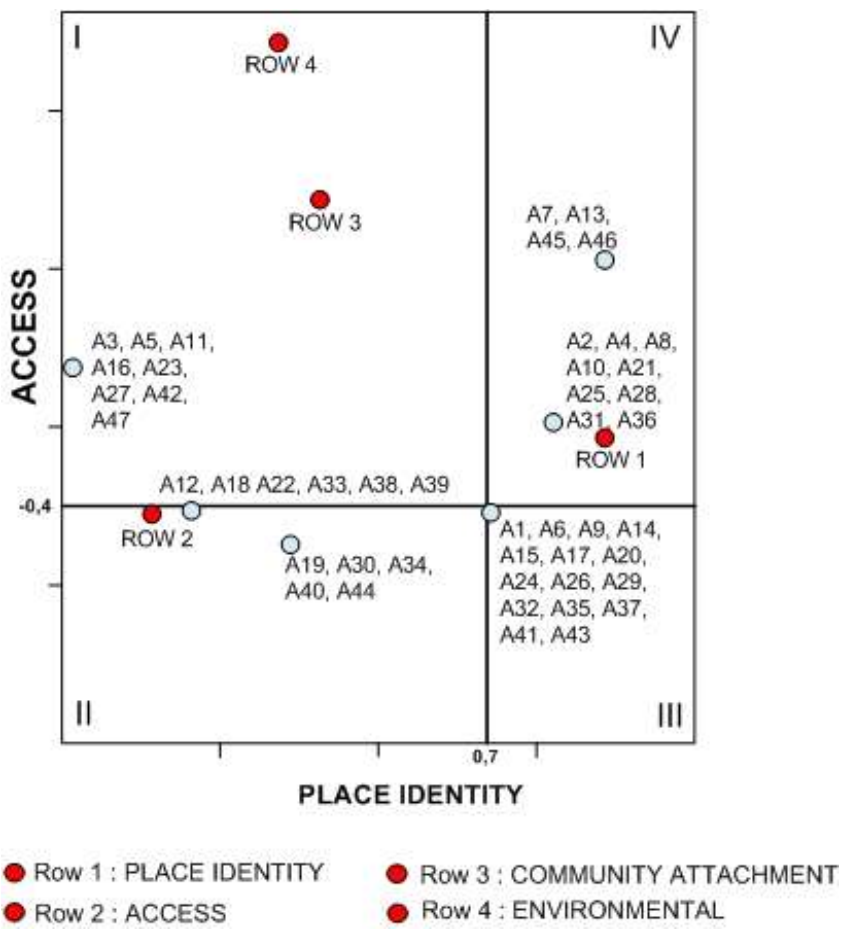

Fig. 1: Multidimensional Scaling Map on Residents' Perception of Residences in RT 02 RW 09 Tulusrejo Village

Explanation on the spatial map related to residents' perception on RT 03 as the place to live (Fig. 2) is presented as follows.

1. There are two big groups in the spatial map of residents' perception in RT 03 which is divided into accessibility group and self-identity group.

2. Social condition (row 3) and environmental condition (row 4) are not their main reason for choosing where to live since there are no respondents who pick the social condition (row 3) and environmental condition (row 4) as their reasons.

3. Based on the dimension 1 (accessibility): coordinate points in the right side exhibit similar perception related to accessibility.

4. Based on the dimension 2 (self-identity): coordinate points in the upper side exhibits similar perception influenced by self-identity.

5. Quadrant I consists of B3, B9, B22, B28, B31, B34, B39, B44, and B48 who picked self-identity (row 1) as the main reason, followed by accessibility (row 2), social condition (row 3 ) and environmental condition (row 4).

6. Quadrant II consists of B4, B6, B8, B14, B15, B43, B47, and B49 who chose self-identity (row 1) as the main reason, followed by social condition (row 3), accessibility (row 2) and environmental condition (row 4). However, respondent B17 chose self-identity (row 1) as the main reason, followed by social condition (row 3), environmental condition (row 4) and accessibility at the last (row 2).

7. Quadrant III consists of three groups:

a) B1, B2, B5, B7, B11, B12, B13, B16, B29, B33, $\mathrm{B} 35, \mathrm{~B} 36$, and $\mathrm{B} 40$ are respondents who chose accessibility (row 2) as the main reason, followed by social condition (row 3), environmental condition (row 4) and self-identity (row 1).

b) B18 and B21 are respondents who chose accessibility (row 2) as the main reason, followed by the environmental condition (row 4), social condition (row 2) and self-identity (row 1).

c) B50 is the respondent who chose accessibility (row 2) as the main reason, followed by the self-identity (row 1), social condition (row 3) and the environmental condition (row 4).

8. Quadrant IV consists of 2 groups which are:

a) B19, B20, B26, B27, B30, B32, B37, B38, B41, $\mathrm{B} 42, \mathrm{~B} 45, \mathrm{~B} 46, \mathrm{~B} 50$ are respondents who chose the accessibility (row 2) as the main reason, followed by self-identity (row 1), social condition (row 3), and environmental condition (row 4).

b) B10, B23, B24, B25 are respondents who choose accessibility (row 2) as the main reason, followed by social condition (row 3), environmental condition (row 4) and self-identity (row 1).

Based on the grouping, it can be seen that 33 respondents (65\%) choose accessibility as the main reason, and 18 respondents $(35 \%)$ choose the self-identity to live in RT 03 RW 09 Tulusrejo Village. 


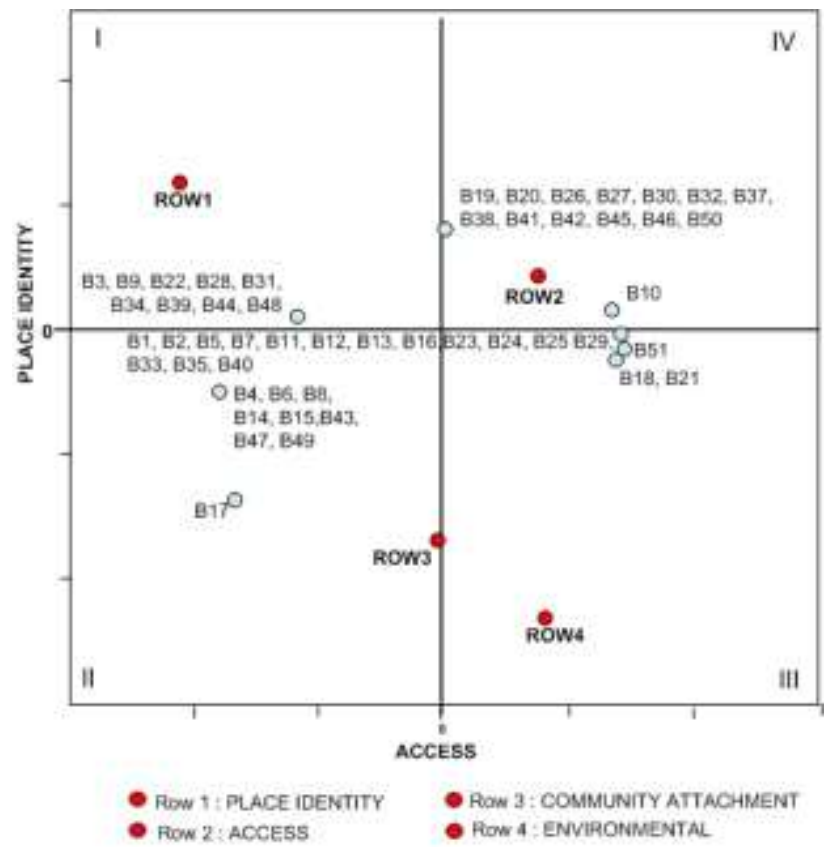

Fig. 2: Multidimensional Scaling Map of Residents' Perception on residing in RT 03 RW 09 Tulusrejo Village.

Overall, residents of RT 02 and RT 03 RW 09 Tulusrejo village have similar perception and are enrolled in some organization. There are also some respondents who join more than 1 organization and act as mediators to make spread information. However, there are also some respondents who have similar perception but they lacked social intimacy as seen from their organizational membership. Generally, the main reason of residing is related to self-identity (row 1) and accessibility (row 2). This different form of perception also cannot be separated apart from respondents' characteristic which is affected by an intern and extern influences.

\section{Acknowledgement}

The researchers would like to send their gratitude for the colleagues who are members of the postgraduate civil engineering in Brawijaya University who have given their support, suggestions, as well as positive inputs. Furthermore, the researchers are so thankful for the community in RT 02 and RT 03 RW 09 Tulusrejo village who have given their data as input in this research.

\section{References}

Borg I and Groenen PJ (2005) Modern multidimensional scaling: Theory and applications. Springer Science \& Business Media

Hummon DM (1992) Community attachment: Local sentiment and sense of place. In: Altman I and Low SM (eds.) Place Attachment. pp. 253-278, New York: Random House.

Kyle GT, Mowen AJ, Tarrant M. (2004) Linking place preferences with place meaning: An examination of the relationship between place motivation and place attachment. Journal of environmental psychology 24(4): 439-454.

Lewicka M (2011) Place attachment: How far have we come in the last 40 years? Journal of environmental psychology 31(3): 207-230.

Wasserman S and Faust K (1994) Social network analysis: Methods and applications. Cambridge university press. 